\title{
Políticas socinis
}

\section{Estratégins de governamentalidade}

\author{
Vinícius Armiliato ${ }^{102}$
}

\section{RESUMO}

A partir da consideração de que as políticas públicas são ações racionalizadas pelo Estado, pretendo apontar neste artigo o ponto de contato das discussões teóricas das políticas públicas, com a ideia de governamentalidade biopolítica proposta por Michel Foucault. $\mathrm{O}$ artigo está delimitado em torno das políticas sociais, marcantes no surgimento e desenvolvimento do Welfare State. São apontados alguns fatores que fizeram do Estado um operador da provisão de determinados serviços, sob a ótica do conceito da governamentalidade biopolítica. Quais seriam os fins das políticas sociais e de que forma elas passam a ser importantes para a manutenção do Estado? Uma das interpretações sobre políticas sociais é que estas se caracterizam como manobras que o Estado lança mão com o fim de manter-se em equilíbrio enquanto entidade autônoma. Para tanto é preciso canalizar, direcionar, controlar os fluxos da população, oferecendo impulso para desenvolvimento em determinados setores quando conveniente ou, de modo contrário mas também conveniente, reduzindo incentivos. As políticas sociais funcionariam como uma das ferramentas que assumem um compromisso com a potência do próprio Estado. A governamentalidade biopolítica, escancarada como um controle dos fluxos da população, incentivando ou não que determinadas classes acessem determinados saberes e lugares, pode ser contemplada lançando um olhar para programas de políticas sociais, como de previdência, educação, geração de emprego, entre outros.

Palavras-chave: Governamentalidade. Políticas Sociais. Estado. Foucault.

\section{ABSTRACT}

From the consideration of that public policy actions are rationalized by the state, I want to point out in this article the contact point of the theoretical discussions of public policy, with the idea of biopolitical governmentality proposed by Michel Foucault. Article is delimited around social policies, outstanding in the emergence and development of the Welfare State. Have pointed out some factors that made the state an operator in the provision of certain services, from the perspective of

102 Mestrando em Filosofia (PUC-PR) e Especialista em Sociologia Política (UFPR). Possui graduação em Psicologia (PUC-PR) e em Artes Cênicas (FAP). E-mail: vinicius.arm@gmail.com 
the concept of governmentality biopolitics. What would be the purpose of social policies and how they come to be important for the maintenance of the rule? One of the interpretations of social policies is that these maneuvers are characterized as the state launches hand in order to remain in balance as an autonomous entity. Therefore it is necessary to channel, direct, control the flow of population, providing impetus for development in certain sectors or when convenient, so contrary but also convenient, reducing incentives. Social policies work as one of the tools that assume a commitment to the power of the state itself. The biopolitical governmentality, gaping like a control population flows, encouraging or not certain classes knowledge and access to certain places, can be contemplated casting a look of social programs such as welfare, education, employment generation, among others.

Keywords: Governmentality. Social Policies. State. Foucault.

Pretendo, com este trabalho, situar o debate teórico em torno das políticas sociais, apontando alguns fatores que tornaram o Estado um operador da provisão de determinados serviços. Para tal estudo, pretendo contemplar as políticas sociais sob a ótica do conceito da governamentalidade biopolítica de Michel Foucault. Procuro estabelecer quais seriam os fins das políticas sociais e de que forma elas passam a ser importantes para a manutenção do Estado ou, para o exercício da governamentalidade. A hipótese que se procurará demonstrar é a de que as políticas sociais são a materialização da governamentalidade biopolítica, dentro daquilo que Michel Foucault entende por governamentalidade.

\section{A EMERGÊNCIA DA ABORDAGEM TEÓRICA DAS POLÍTICAS PÚBLICAS}

As políticas públicas ganharam nas últimas décadas significativa visibilidade perante as ciências sociais. Essa visibilidade fez com que se elaborassem estudos sobre as instituições que as regem, seus processos de elaboração, bem como os de implementação e de avaliação. Frey (2000, p. 214215) aponta que essa área de pesquisa inicia na década de 50, nos EUA, a partir do pressuposto "[...] de que, em democracias estáveis, aquilo que o governo faz ou deixa de fazer é passível de ser (a) formulado cientificamente e (b) analisado 
por pesquisadores independentes" (SOUZA, 2006, p. 22) ${ }^{103}$ Nesse sentido, Souza reforça que

A proposta de aplicação de métodos científicos às formulações e decisões do governo sobre problemas públicos se expandiu depois para outras áreas da produção governamental, inclusive para a política social (SOUZA, 2006, p. 23).

Di Giovanni (2009) cita um ethos pragmático típico da cultura norte americana, no qual o objetivo com as políticas públicas seria o de "[...] fornecer subsídios para ação dos governos ${ }^{104 "}$ (DIGIOVANNI, 2009, p. 8)

Considerando as políticas públicas globalmente, Souza (2006, p. 20) aponta três fatores que viabilizaram um olhar mais apurado para estas: adoção de políticas restritivas de gasto, principalmente nos países em desenvolvimento; novas formas de conceber o papel dos governos na substituição de políticas keynesianas do pós-guerra - nas quais o Estado aparece como um agente indispensável para controlar a economia e estabelecer empregos ${ }^{105}$-, equilibrando o orçamento (relação receita vesus despesa) e restringindo ações do

103 No contexto do final dos anos 40, em decorrência da Guerra Fria, a necessidade de um estudo científico das políticas públicas se evidencia com a criação da RAND Corporation, em 1948, por Robert McNamara: a instituição era composta por matemáticos, sociólogos, engenheiros, entre outros, cujos objetivos eram projetar a guerra comparando-a como um jogo racional, ou seja, pensar as ações do Estado em sua efetividade concreta:

104 Basta citarmos alguns textos mais recentes quanto análise e tipos de políticas públicas, os quais procuram categorizar ações de políticas, bem como propor modelos de implementação, análise e avaliação: CAPELLA, Ana Claudia N. Perspectivas teóricas sobre o processo de formulação de políticas públicas. BIB, São Paulo, n. 61, 2006, pp 25-52.; DI GIOVANNI, Geraldo. As estruturas elementares das políticas públicas. Caderno de Pesquisa. Campinas, NEPP, no 82 2009. SOUZA, Celina. Políticas Públicas: uma revisão da literatura. Sociologias, Porto Alegre, ano 8, no 16, jul/dez 2006, p. 20-45; VIANA, Ana Luiza. Abordagens metodológicas em Políticas Públicas. Caderno de pesquisa. Campinas, NEPP, no 05, 1988; CARLSON, D. Trends and Innovations in Public Policy Analysis. Policy Studies Journal, n. 39: 13-26, 2011. FARIA, Carlos A. P. de. Ideias, conhecimento e políticas públicas: um inventário sucinto das principais vertentes analíticas recentes. Revista Brasileira de Ciências Sociais. São Paulo, vol.18, n. 51, pp. 21-9, fev. 2003. FREY, K. Políticas públicas: um debate conceitual e reflexões referentes à prática da análise de políticas públicas no Brasil. Planejamento e Políticas Públicas. Brasília: IPEA, vol.21. 2000. p. 211-259. LOWI, Theodore. Four Systems of Policy, Politics and Choice. Public Administration Review, 32: 298-310, 1972.

105 Segundo Carvalho "O keynesianismo é uma doutrina ativista, que preconiza a ação do estado na promoção e sustentação do pleno emprego em economias empresariais" (CARVALHO, 2008, p. 571). 
estado na economia e nas políticas sociais; e por fim, em especial nos países da América Latina, a dificuldade em formar coalizões que elaborem e implementem políticas públicas que favoreçam o desenvolvimento econômico e a inclusão social $^{106}$.

Constata-se que no debate teórico sobre as políticas públicas, pretende-se entender os processos que estão envolvidos nas ações do governo. É o que Frey coloca com relação à abordagem das políticas públicas pelas ciências políticas, situando que suas

[...] investigações podem ser voltadas aos resultados que um determinado sistema político vem produzindo. Nesse caso, o interesse primordial consiste na avaliação das contribuições que certas estratégias escolhidas podem trazer para a solução de problemas específicos (FREY, 2000, p. 213).

Destaca-se assim, o caráter científico das análises e modelos, por basearem-se em estruturas formais - governo, decisores, atores, leis, regras, fator tempo, efetivação das ações ou não - considerando as relações entre estas mesmas estruturas.

Di Giovanni (2009) considera as políticas públicas como uma maneira

[...] contemporânea de exercício de poder nas sociedades democráticas, resultante de uma complexa interação entre o Estado e a sociedade, entendida aqui num sentido amplo, que inclui as relações sociais travadas no campo da economia (DI GIOVANI, 2009, p. 5, grifo do autor).

Nota-se uma recorrência nas considerações sobre as ações do governo em si, naquilo que é concreto em suas atividades, passível de mensuração, previsão e correção, independente da figura de atores políticos, bem como de discursos ideológicos ou partidários envolvidos em tais atividades.

Destacamos que o entendimento das políticas públicas enquanto modelo para pensar e visualizar a ação do estado, é categorizado pela literatura em setores, a fim de que se possa estabelecer de forma mais precisa as ações e

106 Di Giovanni (2009) aponta que as políticas keynesianas adotadas no pós-guerra contribuiriam para ampliar as intervenções do estado, em um caráter regulador, na provisão de bens, serviços, pleno emprego e formalização de sistemas de proteção social 
intervenções do governo, na administração do próprio Estado ou, naquilo que compreende a vida social, econômica, ambiental, cultural, entre outras. Kauchakje adverte que "[...] embora a setorialização das políticas públicas seja útil em termos de compreensão de sua abrangência e, também, de ordenamento da gestão pública, isso não significa que elas são estanques" (KAUCHAKJE, 2007, p, 62). Sendo assim, as políticas, nos diferentes setores em que são aplicadas, acabam interferindo-se mutuamente. Segue que as políticas públicas, apesar de dividiremse em setores, apontam para um fim último: a promoção da cidadania:

[...] como uma política pública está estreitamente vinculada a outra, a separação entre elas - no que se refere ao planejamento, orçamento e execução - compromete o alcance da finalidade principal de todas elas individualmente e em conjunto, ou seja, promover condições concretas de cidadania (KAUCHAKJE, 2007, p. 62)

Se considerarmos os requisitos que configuram as democracias modernas (Di Giovanni, 2009), como poder mínimo de planificação nos aparelhos de Estado, existência e coexistência de poderes, direitos de cidadania e, como consequência, o exercício dessa cidadania através da formulação de agendas públicas,

Do ponto de vista histórico, podemos dizer que tais requisitos constituíram-se de modo sempre uniforme, nas sociedades modernas capitalistas desde o século XIX, mas que foram consolidados principalmente depois da segunda guerra mundial (DI GIOVANNI, 2009, p. 5)

Assim, no período do pós-guerra buscou-se, especificamente com as políticas sociais, uma promoção do bem-estar da população e uma manutenção da legitimação do Estado. Para este trabalho, delimitarei a discussão às políticas sociais, a fim de sustentar o objetivo de encontrar pontos de contato destas com os estudos sobre a governamentalidade, de Michel Foucault. Acredito que essa relação é possível pelo fato de que sendo a governamentalidade biopolítica uma racionalização da ação do Estado com relação à população, o manejo teórico das políticas públicas não estaria distante desta mesma racionalização ao considerarmos o destaque que estas ganharam no meio acadêmico e político do pós-guerra, sendo racionalizadas e construídas como ferramentas científicas a fim 
de que se estabelecesse o melhor caminho para as ações do Estado naquele período. Outrossim, tanto as políticas públicas quanto a governamentalidade biopolítica, debruçam-se sobre aquilo que tange a população, à cidadania dessa população, a relação dessa mesma população com a economia, o mercado de trabalho, a previdência, a saúde e a educação. Relação essa que depende da mediação da máquina estatal, como veremos adiante. Para tanto, se faz necessário situar o leitor no debate sobre a emergência das políticas sociais, as quais aparecem fortemente relacionadas na literatura com o Welfare State.

\section{POLÍTICAS SOCIAIS: EMERGÊNCIA E CARACTERÍSTICAS}

A característica das práticas discursivas da cientificidade das ações do Estado também se faz notar quanto às políticas sociais, mesmo antes do momento histórico de serem intituladas como tal. Arretche (1995) investiga a emergência dos programas sociais a partir de uma revisão de literatura das teorias explicativas para o aparecimento destes. As teorias apontam a industrialização crescente durante o século XIX como elemento desencadeante da necessidade de intervenção estatal, naquilo que tange a ações de provisão de serviços aos trabalhadores e àqueles que são incapacitados de competirem no mercado de trabalho (como idosos e crianças).

[...] o homem se tornaria mais socialmente dependente na mesma medida em que se tornasse mais individualizado e mais especializado. Assim, a especialização do trabalho, fruto da industrialização, implicaria em crescimento da dependência individual em relação à sociedade (ARRETCHE, 1995, p. 15).

Para não prejudicar o andamento do processo produtivo, seria necessário tornar o trabalhador capaz de vender sua mão de obra, além de restringir sua mobilidade a determinados espaços da cidade, bem como estabilizá-lo em um mesmo emprego. A partir de uma abordagem que leve em conta documentos do final do século XIX e início do século XX, Topalov aponta que as políticas sociais contribuíram para constituir "[...] as bases da nova organização do sistema de 
poder que, ao mesmo tempo, tanto põe frente a frente quanto une classes dominantes e classes subalternas" (TOPALOV, 1996, p. 23-24). ${ }^{107}$

Legitimar esse poder se torna uma necessidade emergente devido aos problemas demográficos decorrentes do crescimento das cidades, e da necessidade de legitimação social da venda da força de trabalho, eliminando o desemprego voluntário, empecilho para o processo produtivo da indústria.

Podemos ver, então, que suas políticas sociais progressistas (o segurodesemprego e a reforma da moradia) têm sua origem em um projeto educativo relativo aos trabalhadores urbanos e não nas exigências destes últimos. Essas políticas sociais contrariavam dois hábitos bem arraigados nas classes populares: a mobilidade e a intermitência do emprego assalariado e a preferência pelas moradias baratas de seus bairros tradicionais (TOPALOV, 1996, p. 27)

Juntamente com o processo de industrialização, discursos reformistas viabilizaram o condicionamento do trabalhador às necessidades da indústria e às necessidades de organização demográfica. Também da parte dos trabalhadores houve um movimento por direitos. É o que Topalov aponta com a descrição das primeiras organizações sindicais, estas não decorrentes de ideários reformistas, mas sim, da necessidade de contribuir com dificuldades da própria classe trabalhadora.

[...] a colocação da mão-de-obra pelo sindicato e o seguro-desemprego são práticas intimamente vinculadas entre si. O seguro permite que 0 trabalhador sindicalizado sobreviva até que encontre trabalho, podendo, assim, recusar as ofertas de salários inferiores aos da tabela sindical ou provenientes de um empregador que conste na "lista negra" ou esteja submetido ao boicote da organização. $O$ seguro incita o operário a filiarse ao sindicato, e, assim, este fortalece seu controle sobre a oferta de mão-de-obra. (TOPALOV, 1996, p. 29)

A capacitação da mão-de-obra e as mudanças no estilo de vida do trabalhador, foram apropriadas pelos reformadores com vistas a adaptá-los às demandas da industrialização. Aparecerão assim, "questões sociais" a serem resolvidas que, gradativamente, serão divididas em uma miríade de problemas

107 Esping-Andersen também apresenta esse pacto entre a acumulação de capital e os trabalhadores, representado pela implementação gradativa de políticas sociais para a permanência do modo capitalista de produção (ESPING-ANDERSEN, 1991). 
específicos decorrente da aglomeração das pessoas nos centros urbanos, devido à industrialização. Com relação aos problemas urbanos, os reformadores perdem espaço para os especialistas, que passam a aplicar técnicas e modelos específicos de trabalho para cada "problema urbano":

Começa-se a diferenciar "classe operária respeitável" de massas empobrecidas, às quais se classifica, progressivamente, em categorias, cada uma delas sujeita a um tratamento particular e adaptado a uma situação. Assim, os clientes habituais do hospital, do workhouse (asilo) ou das instituições de assistência começaram a ser tratados de forma diferente, segundo sejam situados nas categorias dos velhos indigentes, das mães e crianças sem recursos, dos desempregados, dos vagabundos, dos retardados mentais e dos delinquentes juvenis [...] Desse modo, adquirem autonomia, por exemplo, os problemas do alcoolismo, a tuberculose, a escolarização, a aprendizagem, a moradia, o urbanismo e o desemprego (TOPALOV, 1996, p. 34).

Para Topalov (1996), as medidas pelos agentes do Estado caracterizarão um controle das massas ao lançarem mão de saberes e técnicas específicas de intervenção, visto ser iminente a necessidade de eliminar específicos "problemas sociais". O contexto que permeia as ações dos reformistas ao conferir especificidades a essa "classe operária respeitável", objetivava dar conta da manutenção do processo de industrialização. Seria pertinente e útil passar ao controle do Estado as soluções em provisão de serviços às classes oprimidas diante da industrialização. O resultado disso é a racionalização de ações do estado, a partir da cientificidade dos discursos sobre os "problemas urbanos", a qual legitimará a verdade do trabalho, do salário, da habitação estável, dos cuidados com a saúde, da necessidade da educação formal. Uma virada importante notada por Topalov está nas primeiras elucubrações e ações práticas de política social que, passando pelas mãos e pelos valores e interesses dos filantropos, transferem-se para os novos especialistas "[...] que não falam e atuam para defender os interesses particulares de nenhum grupo, mas em nome dos interesses superiores da sociedade. Esta pretensão está baseada na objetividade da ciência a que servem" (TOPALOV, 1996, p. 36).

O discurso da necessidade de intervenção social aparece no debate político, imiscuindo duas necessidades: a do capital e a da harmonia social. Esse 
discurso, segundo Esping-Andersen, foi atravessado pelos ideários democráticos que, com a industrialização, evidenciavam ainda mais a desigualdade na distribuição de renda para a classe trabalhadora,

A democracia tornou-se o calcanhar de Aquiles de muitos liberais. Enquanto o capitalismo se mantivesse com um mundo de pequenos proprietários, a propriedade em si pouco teria a temer da democracia. Mas, com a industrialização, surgiram massas proletárias, para quem a democracia era um meio de reduzir os privilégios da propriedade (ESPING-ANDERSEN, 1991, p. 86)

O discurso e a ação do estado unia então, a democracia por um lado e a continuidade do processo de industrialização, por outro. As medidas de provisão de serviços que seriam tomadas por parte do Estado, equalizariam as necessidades da economia e as necessidades da classe trabalhadora como "[...] quando os trabalhadores desfrutam de direitos sociais, pois o salário social reduz a dependência do trabalhador em relação ao mercado e aos empregadores e assim se transforma numa fonte potencial de poder $^{108 "}$ (ESPING-ANDERSEN, 1991, p. 89).

Offe e Lenhardt (1984) situam a política social por parte do Estado, como meio viabilizador da transformação no modo de vida do trabalhador (da atividade de camponês para a de operário). As políticas sociais serviriam para o acondicionamento de uma massa de indivíduos a determinadas tarefas. "A política social é a forma pela qual o Estado tenta resolver o problema da transformação duradoura de trabalho não assalariado em trabalho assalariado" (OFFE; LENHARDT, 1984, p. 15). As Políticas Sociais viriam de encontro a uma necessidade de satisfação não só dos trabalhadores, que podem capacitar-se e assim adentrar no mercado de trabalho com melhores condições de renda, como também ao Estado, ao possibilitar um suposto avanço tecnológico, otimizando a

1080 conceito que se enquadraria entre essas duas facetas, segundo Esping-Andersen, seria o de social-democracia "[...] em que a política social resultaria também em mobilização de poder. Ao erradicar a pobreza, o desemprego e a dependência completa do salário, o welfare state aumenta as capacidades políticas e reduz as divisões sociais que são as barreiras para a unidade política dos trabalhadores" (ESPING-ANDERSEN, 1991, p. 89-90). 
produção a partir da capacitação da força de trabalho. As políticas sociais entrariam como uma forma de fazer a massa trabalhadora acompanhar o desenvolvimento do capitalismo: "[...] a transformação em massa da força de trabalho despossuída em trabalho assalariado não teria sido nem é possível sem uma política estatal' (OFFE; LENHARDT, 1984, p. 17).

Para os autores, a aceitação do trabalho assalariado só seria possível se as políticas sociais criassem aparelhos que (a) fizessem os trabalhadores estarem dispostos a oferecer sua capacidade de trabalho, (b) proporcionassem condições para que $o$ trabalho assalariado funcione como tal $e$ (c) equilibrassem quantitativamente tanto uma proletarização passiva (trabalhadores forçados) quanto ativa (trabalhadores demandando uma ocupação). Assim, o Estado seria o agente responsável pela integração da força de trabalho em um status de "normalidade".

[...] a política social não é uma mera "reação" do Estado a "problemas" da classe operária mas contribui de forma indispensável para a "constituição" dessa classe. A função mais importante da política social consiste em regulamentar o processo de proletarização (LENHARDT; OFFE, 1984, p. 22).

A política social é concebida como parte de uma estratégia, pela política do Estado, com mecanismos que assegurem permanência e manutenção da força de trabalho. As instituições do Estado visariam o controle das motivações dos trabalhadores, a adaptação da capacidade de trabalho (preparo técnico) e a regulamentação quantitativa da oferta de força de trabalho (como as políticas sociais que regulam a amplitude da população economicamente ativa, a oferta de creches para que os pais trabalhem, os incentivos para estudar determinadas áreas do conhecimento, ou ainda, o condicionamento do acesso de classes sociais distintas a distintas áreas do conhecimento.

A política social se desenvolve não só em função das necessidades e das exigências dos detentores da força de trabalho, mas sim do processo de transformação dessas mesmas exigências em políticas, cuja mediação é oriunda "[...] de estruturas internas de organização do sistema político, as quais, em 
verdade, decidem se tais 'necessidades' podem ou não ser admitidas como temas que merecem elaboração" (LENHARDT; OFFE, 1984, p. 34).

Nota-se nessa vertente de análise, que o Estado procura oferecer uma manutenção ao modo de produção e, as políticas sociais, seriam os mecanismos utilizados tal. Draibe (1988) aponta que a análise de Offe e Lenhardt, faz visualizar uma espécie de pacto ou troca de benefícios entre classes, pontuando que no pós-guerra o alto crescimento econômico e a ampliação de programas de BemEstar, se deu devido a essa parceria entre política social e política econômica, "[...] sustentada por um consenso acerca do estímulo econômico conjugado com segurança e justiça sociais" (DRAIBE, 1988, p. 55).

Sendo assim, a evasão do trabalhador, além da adequação de seu modo de vida, seria um problema a ser resolvido pelas políticas sociais. O processo produtivo da indústria exigiu um hábito comportamental: "[...] a atividade industrial (na fábrica) exige um novo tipo de trabalhador com novos hábitos, uma nova disciplina, diferente daquela compatível com a atividade produtiva do camponês" ${ }^{109}$ (ARRETCHE, 1995, p. 9). Além disso, a crescente industrialização tornou o trabalhador um sujeito submetido ao mercado de trabalho, demasiadamente frágil para os avanços e a competitividade da industrialização.

\section{GOVERNAMENTALIDADE BIOPOLÍTICA: CARACTERÍSTICAS QUE TANGEM AS POLÍTICAS SOCIAIS}

Na última aula do curso proferido no Collège de France, entre os anos de 1975 e 1976, intitulado "Em Defesa da Sociedade", Foucault começa a apontar

109 Para Foucault o desenvolvimento aparelhos disciplinares, se deu para alcançar a produtividade máxima dos corpos e o controle das ações dos trabalhadores. "A fábrica parece claramente um convento, uma fortaleza, uma cidade fechada [...] É porque, à medida que se concentravam as forças de produção, o importante é tirar delas o máximo de vantagens e neutralizar seus inconvenientes (roubos, interrupções do trabalho, agitações e 'cabalas'); de proteger os materiais e ferramentas e de dominar as forças de trabalho" (FOUCAULT, 2010, p. 137-138). 
para um novo tipo de poder que aparece se sobrepondo ao poder disciplinar ${ }^{110}$. Candiotto (2011) aponta que a problematização da biopolítica por Foucault,

Pareceu ter provocado na investigação de Foucault um deslocamento, da constituição do indivíduo moderno como homem-máquina no poder disciplinar para a constituição da população, definida não em termos geográficos pelo conjunto de seres humanos pertencentes a uma unidade territorial, mas sim em seu aspecto vital, como espécie vivente agrupada em torno de uma característica biológica peculiar: doença, ascendência genética, insanidade e assim por diante. (CANDIOTTO, 2011, p. 470)

Esse deslocamento fez estender do poder disciplinar, o biopoder. Assim, somente depois de o poder disciplinar se estabelecer e, consequentemente, determinando os comportamentos individuais, é que foi possível o surgimento do biopoder (FOUCAULT, 1999, p. 189). Essa nova técnica de poder, não disciplinar, não voltada para o corpo individual, atua no conjunto, na espécie, na multiplicidade de homens, de maneira que interfere em processos da vida que envolvem o corpo social (nascimento, morte, produção, doença).

Foucault vai delineando nos cursos do Collège de France a questão da população, que vai crescendo aos olhos da mentalidade de governo:

dos problemas do território para os problemas da população, da administração dos recursos para a administração do poder sobre a vida (ou seja, o biopoder), das ameaças exteriores ao Estado para os riscos internos que emergem em relação à população (FIMYAR, 2009, p. 37)

Candiotto aponta que não há uma exclusão entre poder disciplinar e biopolítica, uma vez que

110 Com relação ao poder disciplinar: "[...] nos séculos XVII e XVIII, viram-se aparecer técnicas de poder que eram essencialmente centradas no corpo, no corpo individual. Eram todos aqueles procedimentos pelos quais se assegurava a distribuição espacial dos corpos individuais (sua separação, seu alinhamento, sua colocação em série e em vigilância) e a organização, em torno desses corpos individuais, de todo um campo de visibilidade. Eram também as técnicas pelas quais se incumbiam desses corpos, tentavam aumentar-lhes a força útil através do exercício, do treinamento, etc. Eram igualmente técnicas de racionalização e de economia estrita de um poder que devia se exercer, da maneira menos onerosa possível, mediante todo um sistema de vigilância, de hierarquias, de inspeções, de escriturações, de relatórios: toda essa tecnologia, que podemos chamar de tecnologia disciplinar do trabalho" (FOUCAULT, 1999, p. 288) 
[...] foi a partir dos procedimentos de totalização (regulação biopolítica) e individualização (normalização disciplinar) que racionalidades políticas, como o liberalismo moderno e as várias vertentes do neoliberalismo contemporâneo, puderam ser entendidas como técnicas de governamentalidade (CANDIOTTO, 2011, p. 471).

Foucault procurou estabelecer uma discussão a fim de "[...] analisar o exercício do poder concentrando-se no desenvolvimento das racionalidades governamentais e das tecnologias governamentais a elas relacionadas" (SIMONS; MASSCHELEIN, 2011, p. 123), introduzindo assim o neologismo governamentalidade, uma mentalidade de governo pautada em racionalidades e tecnologias para conduzir os corpos de acordo com a necessidade de manter o Estado. "Nesse sentido a governamentalidade liberal recodifica os cenários do poder disciplinador (como as escolas e as fábricas) para garantir a existência da liberdade com a qual possa agir" (SIMONS, MASSCHELEIN, 2011, p. 124).

Cabe pensar: como poderíamos ler as políticas sociais a partir desse conceito de Foucault? O autor cita o momento em que determinados processos que envolvem a massa da população passam a ser alvo dessa nova técnica de poder, visto que foram os problemas de controle de nascimento, reprodução, fecundidade, natalidade, longevidade, que aparecem a partir da segunda metade do século XVIII, juntamente com problemas econômicos e políticos que "[...] constituíram, acho eu, os primeiros objetos de saber e os primeiros alvos de controle dessa biopolítica" (FOUCAULT, 1999, p. 290).

Aquilo que Foucault chama de biopoder, quanto às intervenções do estado no corpus da população, aparece no debate teórico das políticas públicas como uma das primeiras necessidades de provisão de serviços por parte do Estado a fim de aplacar os problemas sociais e econômicos decorrentes da industrialização crescente: a política social. A emergência dessa política social de provisão de serviços a cargo do Estado, é considerada o elemento central do Welfare State:

Fenômeno do século $X X$, a provisão de serviços sociais, cobrindo as mais variadas formas de risco da vida individual e coletiva, tornou-se um direito assegurado pelo Estado a camadas bastante expressivas da população dos países capitalistas desenvolvidos (ARRETCHE, 1995, p. 1). 
Essa tomada pelo Estado de certa responsabilidade passa a ser alvo da tecnologia biopolítica quando "[...] se lança mão da medição estatística desses fenômenos [natalidade, fecundidade, reprodução, óbitos] com as primeiras demografias" (FOUCAULT, 1999, p. 290). Vai-se desenhando uma metodologia racional de administração, de regulação e controle, através do viés científico que a questão social ganha nas mãos de profissionais especializados em problemas urbanos (engenheiros, urbanistas, psicólogos, pedagogos, assistentes sociais, médicos sanitaristas) ${ }^{111}$.

Com os propósitos de otimizar a administração da vida no âmbito populacional, a biopolítica divide-se em subgrupos - as crianças, a mãode-obra, a terceira idade, empregados/desempregados, refugiados, criminosos, doentes, etc. - que ora contribuem para a prosperidade coletiva da população, ora a refreiam (FIMYAR, 2009, p. 40).

Deve-se contornar o problema dos grupos sociais fora da capacidade produtiva. Com a criação de instituições de assistência, diferentemente daquelas vinculadas à Igreja, desencadeiam-se as primeiras articulações do Estado na providência à população. Agora, seriam "[...] mecanismos muito mais sutis, economicamente racionais [...] de seguros, de poupança individual e coletiva, de seguridade, etc." (FOUCAULT, 1999, p. 291).

Sendo a biopolítica um dos desdobramentos das formas de governamentalidade, Foucault explicita seu objeto:

A biopolítica lida com a população, e a população como problema político, como problema a um só tempo científico e político, como problema biológico e como problema de poder [...] são fenômenos coletivos que só aparecem com seus objetos econômicos e políticos, que só se tornam pertinentes no nível da massa (FOUCAULT, 1999, p. 293).

No momento da industrialização crescente alguns problemas deverão ser contornados pelo Estado, colocando-se como um agente que visa equilibrar a economia com a política da nação. Dessas tentativas de manter o Estado

111 'Os 'problemas sociais' assim construídos pelos novos profissionais adquirem a qualidade de realidades objetivas [...] Ficam, deste modo, despolitizados e escapam ao âmbito das controvérsias fictícias e perigosas do enfrentamento democrático" (TOPALOV, 1996, p. 37). 
enquanto aparelho equilibrado, dentro do qual determinadas forças se interferem (política, econômica, social), encontramos um ponto observado por Foucault no que diz respeito a um movimento de preservação do Estado. A racionalidade técnico-científica das práticas de governo se apresenta, aparentemente, com um fim em si mesma. O objetivo das políticas sociais de fornecer auxílio aos trabalhadores, pobres e inválidos, não viria depois de um objetivo maior, como o da preservação do Estado? Vale citar uma passagem de Foucault: "O desígnio de uma tal arte de governar é precisamente o de não reforçar o poder que um príncipe pode exercer sobre seu domínio. Seu objetivo é reforçar o próprio Estado" (FOUCAULT, 2006, p. 376, grifo meu).

Passariam a se constituir saberes voltados para a imanência do Estado enquanto fim último da política e da economia. É notável encontrarmos considerações sobre como o Estado está com uma "boa saúde" financeira, como o IDH do Estado tem "se desenvolvido", como a política externa e interna tem "se comportado". Expressões que denotam a aplicação de uma racionalidade para um objeto abstrato, o aparelho estatal. E é então que Foucault utiliza a expressão "razão do Estado" para caracterizá-lo, após distinguir o Estado contemporâneo do Estado cujo poder está nas mãos de um soberano:

[...] a razão de Estado não é uma arte de governar segundo as leis divinas, naturais ou humanas. Este governo não tende respeitar a ordem geral do mundo. Trata-se de um governo em concordância com a potência do Estado. É um governo cujo objetivo é aumentar essa potência em um quadro extensivo e competitivo (FOUCAULT, 2006, p. 376).

Notamos com Foucault um olhar para um Estado racionalizado com um fim em si mesmo, respondendo a uma suposta demanda de organização social. A concepção de Estado, evidentemente, passa a existir depois de instauradas uma série de necessidades decorrentes da industrialização. Uma espécie de manutenção das novas formas de existência e dos deslocamentos da população (como do campo para a cidade) e da abertura das cidades para intercâmbio de mercadorias e constituição do livre mercado. Nesse livre mercado, cujo fim último seria o lucro, notou-se a necessidade de uma regulação deste lucro para a 
pertinência do sistema capitalista. Aparece assim a necessidade de uma máquina, instituição, aparelho, capaz de regular os interesses econômicos e a manutenção do mercado capitalista. Polanyi (2000) aponta que após a Revolução Francesa, impulsionaram-se os interesses econômicos pela paz, de forma a deixar estabelecer negócios pacíficos entre as nações ${ }^{112}$. E o interesse, segundo o autor, era universal. Vale citar que as guerras passaram a ser suprimidas, ou foram muito bem pensadas a fim de buscar um equilíbrio entre as grandes potências da Europa. (POLANYI, 2000, p. 23)

O contexto do qual trata o autor, de quando as nações começaram a agir de forma a manter um equilíbrio na Europa (durante o século XIX), toca os apontamentos de Foucault quanto a "arte de governar", visto ser necessário, naquele contexto, assegurar os benefícios que os Estados vinham ganhando, decorrentes dos avanços tecnológicos e do livre comércio. Seria preciso instaurar uma "arte de governar", algo que regulasse e que atravessasse os interesses de todas as nações europeias, mantendo o equilíbrio interno e externo. É então que aparece a tarefa da polícia, de uma autoridade pública encarregada em manter o equilíbrio e o crescimento de uma nação, regulando suas forças internas e as forças de nações vizinhas.

Só se pode efetivamente manter a balança e o equilíbrio na Europa na medida em que cada um dos Estados tenha uma boa polícia que Ihe permita fazer suas próprias forças crescerem. E, se o desenvolvimento não for relativamente paralelo entre cada uma dessas polícias, vamos ter

112 Algumas vezes evitavam-se as guerras removendo deliberadamente as suas causas, se isto envolvia apenas o destino de potências pequenas. Controlavam-se as pequenas nações e impedia-se que perturbassem o status quo de qualquer forma que pudesse precipitar uma guerra. A invasão holandesa da Bélgica, em 1831, levou à neutralização daquele país na ocasião. Em 1855 a Noruega também foi neutralizada. Em 1867 o Luxemburgo foi vendido à França pela Holanda; a Alemanha protestou e Luxemburgo foi neutralizado. Em 1856, a integridade do Império Otomano foi declarada essencial para o equilíbrio da Europa e o Concerto da Europa procurou sustentar aquele império; após 1878, quando sua desintegração foi considerada essencial para aquele equilíbrio, promoveu-se o seu desmembramento da mesma maneira ordenada, embora em ambos os casos a decisão significasse vida e morte para inúmeros pequenos povos. Entre 1852 e 1863 foi a Dinamarca, e entre 1851 e 1856 foram as Alemanhas que ameaçaram perturbar o equilíbrio, e em cada um dos casos os pequenos estados foram forçados a se conformar pelas Grandes Potências. Nesses exemplos, a liberdade de ação a elas oferecida pelo sistema foi usada pelas Potências para alcançar um interesse conjunto - que aconteceu ser a paz.(POLANYI, 2000, p. 23, grifo meu). 
fatos de desequilíbrio. Cada Estado, para não ver a relação das forças se inverter em seu desfavor, deve ter uma boa polícia. E chegaremos rapidamente à consequência, de certo modo paradoxal e inversa, que consistirá em dizer: mas, afinal, se no equilíbrio europeu há um Estado, mesmo que não seja o meu, que tenha uma má polícia, vamos ter um fenômeno de desequilíbrio. Por conseguinte, é preciso zelar para que, mesmo nos outros Estados, a polícia seja boa. Portanto, o equilíbrio europeu dará ao conjunto dos Estados o direito de zelar para que a polícia seja boa em cada um desses Estados (FOUCAULT, 2008, p. 423).

Polícia é o termo usado por Foucault, mas fica claro que se trata do que denominamos hoje por políticas públicas, sendo as políticas sociais talvez as que mais se destaquem na literatura que o autor apresentará para explicitar sua função.

É a partir dessa gênese da formação de políticas que visassem o equilíbrio do Estado, tomando seus cidadãos enquanto população, enquanto força a qual é preciso direcionar (para a indústria, para o comércio, para o exército, para a academia, enfim, para onde convir se for para manter o equilíbrio do Estado), Foucault aponta um instrumento comum utilizado para mensurar o equilíbrio europeu e a direcionar a organização da polícia: a estatística. E a estatística será o instrumento que permitirá o controle, passível de comparação com outros Estados, das forças do próprio Estado: quem é a população (jovens, velhos, ativos, inativos), o exército, os recursos naturais, como está a produção e o comércio, o status da circulação monetária. ${ }^{113}$ A estatística permite ao Estado especular as forças atuais bem como aquelas ainda a serem desenvolvidas:

A estatística é o saber do Estado sobre o Estado, entendido como saber de si do Estado, mas também saber dos outros Estados. E é nessa medida que a estatística vai se encontrar na articulação dos dois conjuntos tecnológicos [que são o equilíbrio europeu e a organização da polícia]. (FOUCAULT, 2008, p. 424).

As políticas seriam ações do Estado, pelo Estado. Seria uma forma de pensar uma nação independente da figura de um soberano. O Estado passa a ser o soberano e não mais o nome de um sujeito. Assim, estatística aparece como um

113 "Para que o equilíbrio seja efetivamente mantido na Europa, é preciso que cada Estado possa, primeiro conhecer suas próprias forças, segundo conhecer, apreciar as forças dos outros e, por conseguinte, estabelecer uma comparação que possibilitará, justamente, acompanhar e manter o equilíbrio" (FOUCAULT, 2008, p. 424) 
instrumento científico que prescinde da figura de uma pessoa, de um motivo individual para seus achados. A estatística, a partir de suas inúmeras medições, vai tecendo uma colcha de resultados que significam o Estado. Determinado Estado não é a figura de um rei, mas aquilo que a estatística apontou: um Estado é os seus recursos naturais, é sua capacidade produtiva, é o montante de trabalhadores, é seu arsenal bélico, é sua acumulação de capital, entre todos os dados passíveis de quantificação. A cada um desses dados atribuem-se siglas, traçam-se paralelos com outras nações, observa-se evoluções, regressões, estabilidade, enfim, entre dados estatísticos. Ao citar teóricos que apontassem para a necessidade de uma manutenção das cidades, do comércio e da sociedade, é possível resgatar em Foucault o papel das polícias como atuantes na formação do Estado tal como o conhecemos hoje e, tal como provê certos serviços sociais, como também conhecemos hoje.

O autor cita o compêndio de De Lamare ${ }^{114}$, escrito no início do século XVIII, e uma proposta de programa de Estado policiado, escrita por Turquet de Mayerne ${ }^{115}$ em 1611, a fim de explicitar as formas de organização do Estado propostas pela literatura desses séculos. Nestas percebe-se que os teóricos recorrem a uma regulamentação das ações do Estado sobre si e sobre a população, através do conceito de polícia ${ }^{116}$.

Com Turquet, citado por Foucault, pode-se facilmente correlacionar sua proposta com o que hoje se teoriza como políticas sociais. Segundo Foucault, ele propõe a criação de conselhos cuja responsabilidade era manter a ordem pública. Esses conselhos se dividiriam entre os que velariam pelas pessoas e os que velariam pelos bens. Dois seriam os que cuidariam das pessoas. Um "[...] se ocuparia da educação, determinaria os gostos e as aptidões de cada um e escolheria os ofícios - os ofícios úteis: toda pessoa com mais de 25 anos devia

114 LAMARE, N. de. Traité de La Police, Paris: Jean Cot., 1975, 2 vol. Apud FOUCAULT, 2006.

115 MAYERNE, L. Turquet de. La monarchie aristodémocratique, ou le gouvernement composé dês trois formes de legitimes republiques. Paris: J. Berjon, 1611, apud FOUCAULT, 2006.

116 "Por 'polícia' eles não entendem uma instituição ou um mecanismo funcionando no seio de Estado, mas uma técnica de governo própria ao Estado; domínios, técnicas, objetivos que apelam a intervenção do 'Estado'” (FOUCAULT, 2006, p. 377) 
ser inscrita em um registro indicando sua profissão" (FOUCAULT, 2006, p. 378). O outro conselho

[...] devia se ocupar do aspecto negativo da vida: dos pobres (viúvas, órfãos, velhos) necessitados; das pessoas sem emprego; daquelas cujas atividades exigiriam uma ajuda pecuniária; mas também da saúde pública - doenças, epidemias - e de acidentes tais como incêndios e inundações (FOUCAULT, 2006, p. 378).

A partir do autor apresentado por Foucault, notamos forte correlação com a provisão de serviços tomada pelo Estado para a população, cujo fim último seria potencializar o próprio Estado: "Como forma de intervenção racional exercendo o poder político sobre os homens, o papel da polícia é de lhes dar um pequeno suplemento de vida; e, assim fazendo, de dar ao Estado um pouco mais de força" (FOUCAUT, 2006, p. 379).

Em seguida, Foucault aponta o compendium de De Lamare, escrito em 1705, e que apresenta quais seriam as atividades que a polícia deveria ocupar, no interior do Estado ${ }^{117}$.

A lógica das intervenções da polícia seria a da preservação da vida e, mais especificamente, da vida em sociedade. Mas o que devemos chamar a atenção não é somente o caráter único de intervenção do Estado a fim de garantir a felicidade da nação, mas sim, o de garantir seu próprio vigor enquanto Estado. É o que define um texto de 1756 , citado por Foucault, quanto ao que o autor ${ }^{118}$ define como "[...] o objetivo da arte moderna de governar ou da racionalidade estatal: desenvolver esses elementos constitutivos da vida dos indivíduos de tal forma que seu desenvolvimento reforce também a potência do Estado" (FOUCAULT, 2006, p. 383).

Retomando o trabalho de Arretche (1995), as políticas sociais são pensadas com o crescimento das cidades e os problemas consequentes desse

117 "1) a religião; 2) a moralidade; 3) a saúde; 4) as provisões; 5) as estradas, pontes, calçadas e edifícios públicos; 6) a segurança pública; 7) as artes liberais (no todo as artes e as ciências); 8) o comércio; 9) as fábricas; 10) os empregados domésticos e carregadores; 11) os pobres" (FOUCAULT, 2006, p. 380)

118 JUSTI, J. H. Gottlobs Von. Grundsätze der Policey-Wissenschaft. Göttingen: A. Van den Hoecks, 1756, apud FOUCAULT, 2006, p. 382. 
crescimento, devido essencialmente à industrialização. Nesse contexto, a biopolítica seria um conjunto de práticas representadas na tentativa de racionalizar a ação do governo, com relação aos problemas da população ${ }^{119}$. O Estado procuraria maneiras de intervir não só no nível do individual ${ }^{120}$, como também no nível da população:

[...] trata-se sobretudo de estabelecer mecanismos regulares que, nessa população global com seu campo aleatório, vão poder fixar um equilíbrio, manter uma média, estabelecer uma espécie de homeostase, assegurar compensações (FOUCAULT, 1999, p. 293)

E o que seriam determinados programas do Estado senão uma forma de assegurar certa homeostase na rede de relações entre economia e política? Não seria uma extensão das primeiras intervenções desse mesmo Estado para regular a economia, no início do capitalismo, como descreve Polanyi (2000). Assim, cada ação do estado substancializa o exercício da governamentalidade biopolítica no controle e na condução dos fluxos da população. O fim seria a permanência e a pertinência do Estado enquanto aparelho institucional, além da otimização da força desse estado, enquanto aparelho produtivo. As políticas sociais seriam bases de sustentação desses aparelhos, ao fortalecerem os laços da população com as demandas do capital e ao mesmo tempo, a própria população, na cobertura de direitos estabelecidos em tratados, leis e cartas constitucionais. As políticas sociais caracterizarem-se por ações concretas, que interferem na vida da população, nas escolhas e nos direcionamentos dos fluxos de corpo produtivo do Estado, para as áreas que o Estado, enquanto instituição, demanda para manterse em sua atuação.

Existem alguns recursos que o Estado lança mão a fim de beneficiar seus cidadãos e beneficiar seu próprio sistema, enquanto Estado. Determinados

119 Conceito que passa a existir apenas nesse momento da aglomeração urbana decorrente da industrialização: "Não é exatamente com a sociedade que se lida nessa nova tecnologia de poder [...] não é tampouco com o indivíduo-corpo. É um novo corpo: corpo múltiplo, corpo com inúmeras cabeças, se não infinito pelo menos necessariamente numerável. É a noção de "população'” (FOUCAULT, 1999, p. 292).

120 Como o exercício do poder disciplinar, que apesar de ser exercido em instituições, fechadas e controladas, agia nos corpos: em seu treinamento, para o exército, em sua capacitação, para o trabalho, e em seu pensamento, para os estudos escolares. 


\section{v. I. ก. 2. ดg०. 2013 - ARTIGOS}

incentivos, em determinadas áreas, impulsionam determinados movimentos. Se tomarmos as políticas de educação como exemplo, percebemos uma relação estreita com as políticas de trabalho. Se devido ao avanço tecnológico é necessária a manutenção da força-de-trabalho, qualificando a mão-de-obra, é pertinente fortalecer políticas educacionais específicas, para campos de trabalho nos quais a demanda é maior ou naqueles em que há previsão de crescimento e de consequente necessidade de mão-de-obra futura.

\section{CONSIDERAÇÕES FINAIS}

Como lidar com uma população economicamente ativa crescente que, segundo o IBGE (BRASIL, 2010) aumentou significativamente, correspondendo atualmente a $68,5 \%$ da população, pronta para adentrar no mercado de trabalho e ao mesmo tempo assegurar o direito igual a todos, conforme carta magna estabelecida em 1988, de acesso à educação? Regulamentando os fluxos.

No caso da biopolítica, teríamos explicitamente um direcionamento dos corpos, no sentido de conduzir condutas. Facilita-se a determinados grupos o acesso a políticas específicas, canalizando os fluxos da população através de escolhas individuais. Teríamos assim um dos desdobramentos da biopolítica,

[...] a criação de uma superfície de contato entre o governo dos outros (governo político, doméstico, religioso, educacional) e o governo de si mesmo (autodomínio, autocontrole), entre as tecnologias de dominação e as técnicas de si, em virtude das quais estão estreitamente ligadas a condução dos indivíduos e a maneira pela qual eles mesmos se conduzem. (CANDIOTTO, 2012, p. 127)

Se entendermos a substancialização dessa arte de governar, ou dessa racionalidade estatal nas políticas sociais, podemos observar que as intervenções no corpus da população, são maneiras de administrá-la e direcioná-la para determinados lugares, aparentemente de acordo com o que melhor convir para manter a boa "saúde" do Estado, e não da população. 


\section{REFERÊNCIAS}

ARRETCHE, Marta T. S. (1995). Emergência e desenvolvimento do Welfare State: teorias explicativas. BIB. No. 39. Rio de Janeiro. pp:3 - 40.

BORGES, André. Governança e política educacional: a agenda recente do banco mundial. Rev. bras. Ci. Soc., Jun 2003, vol.18, n. 52, p.125-138.

CANDIOTTO, Cesar. Cuidado da Vida e Cuidado de Si: Sobre a individualização biopolítica contemporânea. Dissertatio. N. 34, pp. 469-491, 2011.

. A governamentalidade em Foucault: da analítica do poder à ética da subjetivação. O Que Nos Faz Pensar? N. 31, fev, 2012.

CAPELLA, Ana Claudia N. Perspectivas Teóricas sobre o Processo de Formu;ação de Políticas Públicas. BIB. N. 61, 2006, pp.-25-52.

CARVALHO, Fernando J. Cardin de. Keynes e o Brasil. Economia e Sociedade. Vol. 17. no.esp. Campinas, dez. 2008, pp. 569-574.

DI GIOVANNI, Geraldo. As Estruturas Elementares das Políticas Públicas.

Caderno de Pesquisa. Campinas, NEEP/UNICAMP, 2009.

DRAIBE, Sônia. Brasil 1980-2000: Proteção e Insegurança Sociais em Tempos de Crise. Cadernos de Pesquisa. N. 65. NEEP: Unicamp, 2005.

DRAIBE, Sônia; HENRIQUE, Wilnês. "Welfare State", crise e gestão da crise: um balanço da literatura internacional. Revista Brasileira de Ciências Sociais. N. 6, vol. 3, fev. 1999.

ESPING-ANDERSEN, Gosta. "As Três Economias Políticas do Welfare State", in: Lua Nova, № 24, set, 1991: 85-116.

FARIA. Carlos Aurélio Pimenta de. Idéias, Conhecimento e Políticas Púbicas: Um inventário sucinto das principais vertentes analíticas recentes. Revista Brasileira de Ciências Sociais. São Paulo, vol. 18, n. 51, pp. 21-9, fev, 2003.

FIMYAR, Olena. Governamentalidade como ferramenta conceitual na pesquisa de políticas educacionais. Educação e Realidade. Vol. 34, n. 2, pp. 35-56, mai/ago, 2009.

FIORI, José Luís. Estado do Bem-Estar Social: Padrões e Crises. PHYSIS: Ver. Saúde Coletiva, Rio de Janeiro, vol.6, n.2, pp. 129-147, 1997. 
FOUCAULT, Michel. Em Defesa da Sociedade. São Paulo: Martins Fontes, 1999. 2006

. Estratégia, Poder-Saber. 2. Ed. Rio de Janeiro: Forense Universisária, . Segurança, Território, População. São Paulo: Martins Fontes, 2008.

. Vigiar e Punir. 34. Ed. Petrópolis: Vozes, 2010

FREY, K. Políticas públicas: um debate conceitual e reflexões referentes à prática da análise de políticas públicas no Brasil. Planejamento e Políticas Públicas. Brasília: IPEA, vol.21. 2000. p. 211-259

IBGE. Censo Demográfico 2010: características gerais da população, religião e pessoas com deficiência. IBGE: Rio de Janeiro, 2012. Disponível em: <ftp://ftp.ibge.gov.br/Censos/Censo_Demografico_2010/Caracteristicas_Gerais_R eligiao_Deficiencia/caracteristicas_religiao_deficiencia.pdf>. Acesso em: $15 / 07 / 2012$

KAUCHAKJE, S. Gestão pública de serviços sociais. Curitiba: IBPEX, 2007

LENHART, G. e OFFE, C.. Teoria do Estado e Política Social. Tentativas de explicação político-sociológica para as funções e os processos inovadores da política social In: OFFE, C. Problemas estruturais do Estado capitalista. Rio de Janeiro: Tempo Brasileiro, 1984.

POLANYI, Karl. A Grande Transformação: as origens de nossa época. 2. Ed. São Paulo: Campus, 2000.

SIMONS, Maarten; MASSCHELEIN, Jan. Sociedade da Aprendizagem e Governamentalidade: uma introdução. Currículo sem Fronteiras, v. 11, n. 1, pp. 121-136, jan/jun 2011.

SOUZA, Celina. Políticas Públicas: uma revisão de literatura. Sociologias: Porto Alegre, ano 8, n. 16, jul/dez 2006, p. 20-45.

TOPALOV, Christian. Da questão Social aos Problemas Urbanos. Cidade, povo e nação. Rio de Janeiro: Civilização Brasileira, 1996. 